\title{
Genetic and epigenetic regulation of abdominal aortic aneurysms
}

\author{
Kevin D. Mangum ${ }^{1}$ @ । $\quad$ Mark A. Farber ${ }^{2}$
}

${ }^{1}$ Section of Vascular Surgery, Department of Surgery, University of Michigan, Ann Arbor, Michigan

${ }^{2}$ Division of Vascular Surgery, UNC Department of Surgery, Chapel Hill, North Carolina

Correspondence

Kevin D. Mangum, Section of Vascular Surgery, Department of Surgery, University of Michigan, Ann Arbor, MI.

Email: kevmangu@med.umich.edu

Peer Review

The peer review history for this article is available at https://publons.com/publon/10. 1111/cge.13705.

\begin{abstract}
Abdominal aortic aneurysms (AAAs) are focal dilations of the aorta that develop from degenerative changes in the media and adventitia of the vessel. Ruptured AAAs have a mortality of up to $85 \%$, thus it is important to identify patients with AAA at increased risk for rupture who would benefit from increased surveillance and/or surgical repair. Although the exact genetic and epigenetic mechanisms regulating AAA formation are not completely understood, Mendelian cases of AAA, which result from pathologic variants in a single gene, have helped provide a basic understanding of AAA pathophysiology. More recently, genome wide associated studies (GWAS) have identified additional variants, termed single nucleotide polymorphisms, in humans that may be associated with AAAs. While some variants may be associated with AAAs and play causal roles in aneurysm pathogenesis, it should be emphasized that the majority of SNPs do not actually cause disease. In addition to GWAS, other studies have uncovered epigenetic causes of disease that regulate expression of genes known to be important in AAA pathogenesis. This review describes many of these genetic and epigenetic contributors of AAAs, which altogether provide a deeper insight into AAA pathogenesis.
\end{abstract}

\section{KEYWORDS}

abdominal aortic aneurysm, chromatin, DNA methylation, epigenetic, genetic, histone modification, long non-coding RNA, microRNA, single nucleotide polymorphism

\section{1 | CLINICAL RELEVANCE AND EPIDEMIOLOGY OF ABDOMINAL AORTIC ANEURYSMS}

\begin{abstract}
Abdominal aortic aneurysms (AAAs) are found in $~ 8 \%$ of individuals older than $65 .{ }^{1}$ As the 15 th leading cause of death in patients over 65 , death from AAAs is as common as that from certain cancers. ${ }^{2}$ Modifiable risk factors associated with AAA include smoking, diabetes, hypertension, and coronary artery disease. ${ }^{3}$ Smoking in particular results in a 5-fold increase in AAA risk. ${ }^{4}$ In contrast, nonmodifiable factors such as family history and male gender are also significant risk factors, suggesting a genetic component to AAA pathogenesis. ${ }^{5}$ Twin studies also demonstrate that AAAs have a very high degree of hereditability. ${ }^{6}$ While AAAs are found more commonly in men, women are more likely to present with ruptured aneurysms and rupture at smaller aortic diameters than men. ${ }^{7,8}$ This
\end{abstract}

is likely due to sex-dependent differences in aneurysm progression and suggests a need for lower threshold for aneurysm repair in women than current guidelines suggest. ${ }^{9}$ While AAAs are found more frequently in men, there seems to be a greater genetic contribution in women, since relatives of females have higher incidence of AAAs. ${ }^{10}$

By far the most feared complication of AAA is rupture, which is associated with a $65-85 \%$ risk of death. ${ }^{11,12}$ Prevalence of hospitalization from rupture in the United States has decreased from 10 to 7 per 100000 from 2007 to 2012, respectively, and risk of rupture increases after age $50 .^{2}$ Risk of rupture also increases substantially with increasing vessel diameter, particularly at nonorthogonal diameters between 6.5 and $7.4 \mathrm{~cm}$ for men (odds ratio, 3.9). ${ }^{11}$ Increased wall stiffness, calcification, inflammation, intra-luminal thrombus, and peak wall stress all increase rupture risk as well. ${ }^{13-15}$ Other complications include infected, or mycotic, aneurysms, which occur in up to $3 \%$ of 
patients with AAAs and also have a $15.4 \%$ risk of rupture. ${ }^{16}$ Aortoenteric and aortocaval fistulas, which are connections between the aorta and intestine or inferior vena cava, respectively, are potentially catastrophic complications of AAAs. Although they account for $<1 \%$ of aortic aneurysms, aortocaval fistulas are associated with nearly $55 \%$ mortality. ${ }^{17}$

The United States Preventative Task Force (USPSTF) recommends one time ultrasound screening for AAA in men between 65 and 75 who have ever smoked, and women older than 65 with a smoking history may also benefit. ${ }^{18}$ Elective AAA repair is recommended once an aneurysm reaches $5.0 \mathrm{~cm}$ (orthogonally) in women, $5.5 \mathrm{~cm}$ in men, or grows by 0.6 to $0.8 \mathrm{~cm}$ per year. Depending on age, comorbidities, and vascular anatomy, the patient may undergo either elective endovascular aortic repair (EVAR) or open repair. Open AAA repair is generally recommended for younger patients, individuals with complex ilio-femoral anatomy precluding vascular access, and patients with hostile aneurysm neck anatomy. ${ }^{19}$ In contrast, EVAR should be considered in patients with suitable aortic anatomy, especially in older individuals who are higher risk candidates for open repair. Importantly, challenging vascular anatomy is not an absolute contraindication to EVAR, as several adjunctive techniques and new devices can help facilitate access. ${ }^{20,21}$

\section{2 | GENETIC CAUSES OF AAA PATHOGENESIS}

\section{1 | Mendelian syndromes characterized by AAAs}

Mendelian causes of aortic aneurysms result from single-gene mutations that are often associated with additional phenotypic abnormalities. $^{22}$ While the majority of Mendelian forms of aortic aneurysms affect the aortic root, ascending aorta, and thoracic aorta, some of these same syndromes also cause AAAs. ${ }^{22}$ One commonly cited example of Mendelian AAA is Marfan syndrome, which is an autosomal dominant disorder caused by a mutation in the FBN1 gene. Mutations in TGF $\beta$ R1, TGF $\beta$ R2, and TGF $\beta$ R3 genes cause a Marfan-like syndrome, and perturbed TGF $\beta$ signaling leads to profibrotic changes and increased production of matrix metalloproteinases (MMPs), which cause medial degradation. ${ }^{23,24}$ Marfan syndrome is characterized by aneurysms of the thoracic and abdominal aorta as well as dilatation of the aortic root. ${ }^{25}$ Although the majority of patients with Marfan syndrome have some family history of the disease, $\sim 25 \%$ are de novo cases resulting from spontaneous mutations in Marfan genes. ${ }^{26}$ Loeys-Dietz syndrome (LDS) is another Mendelian aortopathy caused by mutations in the TGF $\beta$ signaling axis, specifically in TGF $\beta R 1$, TGF $\beta$ R2, TGF $\beta 2$, TGF $\beta 3$, SMAD2, and SMAD3 ${ }^{27,28}$ Individuals with Loeys-Dietz have several classic physical findings including vascular, craniofacial, skeletal, and cutaneous defects. While their aneurysms are most often found in the aortic root, up to $12 \%$ of patients have aneurysms affecting the abdominal aorta.

In addition to Mendelian aortic syndromes caused by mutations in TGF $\beta$-related genes, other single-gene aortopathies include those affecting extracellular matrix (ECM) components of the vessel wall.
These include Ehlers-Danlos syndrome, which is caused by mutations in COL3A1, and Osteogenesis imperfecta, which results from mutations in COL1A1 and COL1A2. Aneurysms affecting the proximal branches of the aortic arch, the descending thoracic aorta, and abdominal aorta are all found in Ehlers-Danlos patients. In contrast, mostly ascending aortic arch aneurysms are seen in individuals with Osteogenesis imperfecta, which affects the bones and connective tissues of these patients. AAAs are also seen in patients with homocystinuria and pseudo xanthoma elasticum, which are two autosomal recessive diseases caused by mutations in the CBS and ABCC6 genes, respectively. While aneurysms of the aortic arch and thoracic aorta are also seen in patients with pseudo xanthoma elasticum, AAAs are more common. ${ }^{22}$

\subsection{Non-Mendelian causes of AAAs}

In contrast to Mendelian aortic syndromes, non-Mendelian forms of inheritance are more complex and characterized by variants in several genes. Numerous AAA genetic loci have been identified, and these are discussed below in the context of their respective genetic and molecular pathways. This structure provides a mechanistic framework for beginning to think about how each variant might contribute to AAA pathogenesis. The different variants and associated loci are summarized in Table 1.

\subsubsection{Extracellular matrix}

The ECM provides structural support to blood vessels and also serves important signaling functions to surrounding cells. ${ }^{29}$ ECM turnover is regulated by the MMP family of proteins, and several SNPs associated with AAAs are located within genes encoding ECM components and MMPs. ${ }^{30}$ Saracini et al genotyped over 800 patients and surveyed variants in 12 different genes to find that MMP-3 and MMP-13 polymorphisms (rs3025058 and rs2252070, respectively) were significantly associated with increased AAA risk, while rs2071307 in ELN and rs243865 in MMP-2 trended with decreased risk. ${ }^{31}$ Separate meta-analyses of GWAS for AAA confirmed these results and found that rs3827066 in MMP-9 was also an AAA risk locus. ${ }^{32,33}$ Of note, rs3827066 was also associated with altered expression of nearby genes, PCIF1 and ZNF335.

Several mechanistic research studies have implicated MMPs in AAA pathogenesis. For example, expression of MMP-2 and MMP-9 is increased in human AAA tissue samples. ${ }^{34,35}$ Further, both MMP-2 and MMP-9 knockout mice were protected from aneurysm formation compared to wild-type mice in two separate AAA models. ${ }^{36,37}$ Notably, the rs243865 minor (T) allele is located in the MMP-2 promoter and results in decreased binding of the transcription factor Sp1 and decreased transcription activity compared to the major (C) allele. Although this supports the hypothesis that decreased minor allele-specific MMP-2 expression is protective against AAAs, no study to date has demonstrated a causal relationship between rs243865 and AAAs. ${ }^{38}$

SNPs rs3025058 in MMP-3 and rs2252070 in MMP-13 are both linked to increased AAA risk. ${ }^{31}$ Notably, MMP-3 ablation decreases 


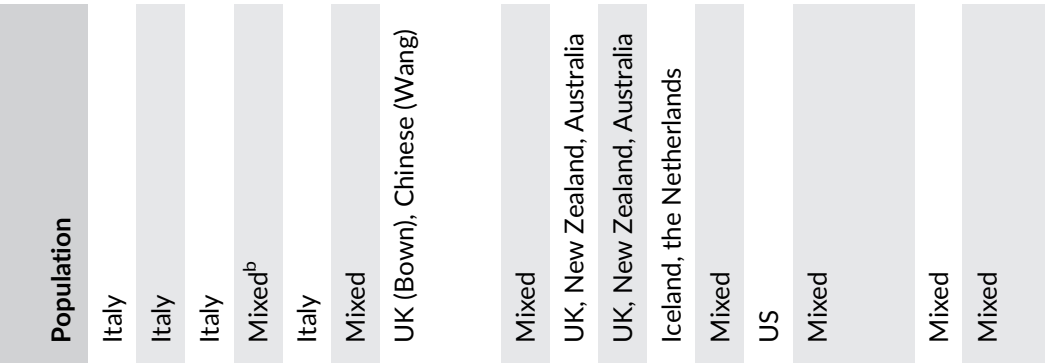

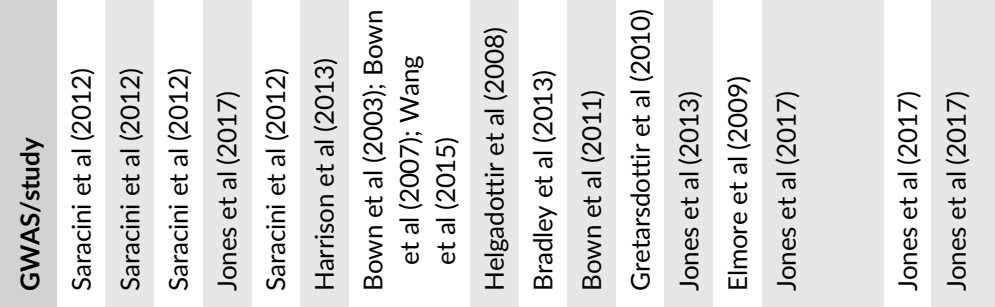

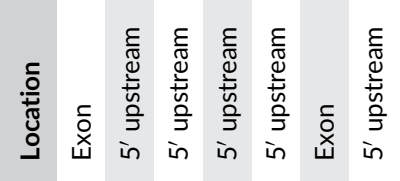

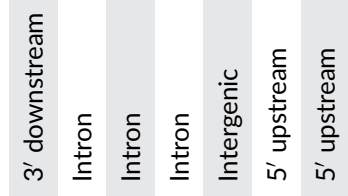

产

产

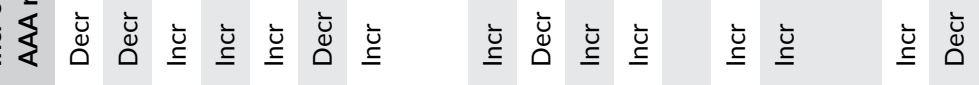

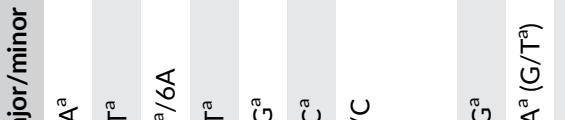

藁

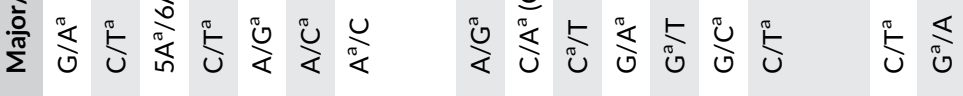

殅 亦

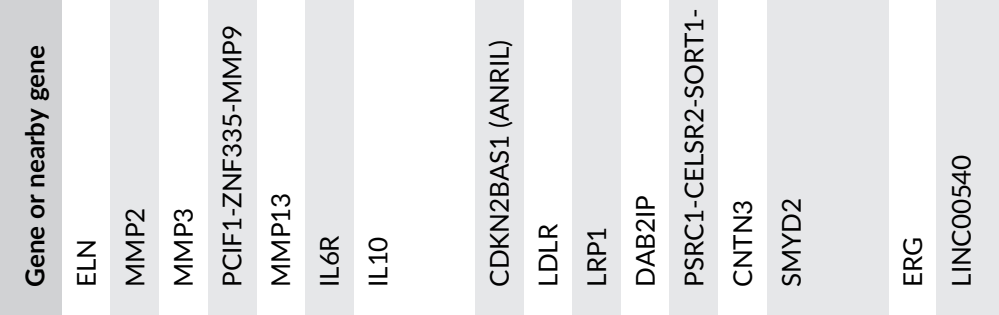

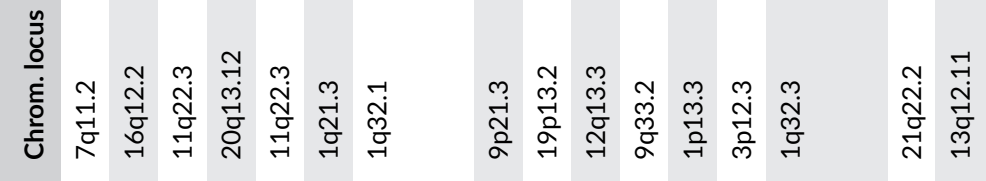

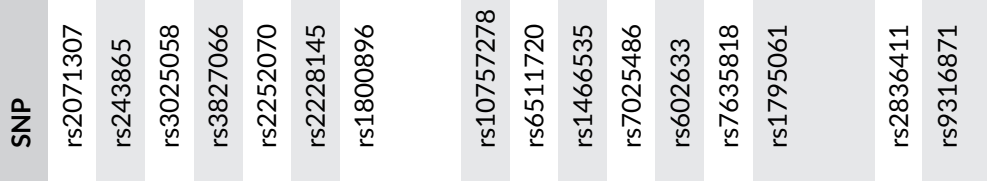

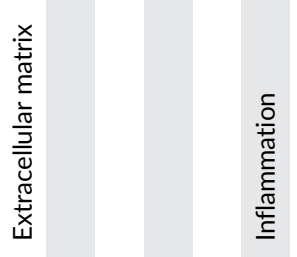

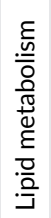


aneurysm formation. ${ }^{39}$ rs3025058 is an insertion-deletion mutation, and the major allele $(5 \mathrm{~A})$ (five adenine residues, compared to six for the minor allele $[6 \mathrm{~A}]$ ) is associated with increased $A A A$ risk and increased MMP-3 promoter activity via an NF-KB-dependent mechanism, lending support to the idea that increased MMP-3 expression and activity contributes to AAA pathogenesis. ${ }^{40-42}$ The rs2252070 minor (G) allele is located within the MMP-13 promoter and associated with increased AAA risk. While no studies exist in endothelial, smooth muscle, fibroblasts, or other vascular cells, experiments in cancer cells demonstrate that the rs2252070 major (A) allele (which is protective) is associated with decreased MMP-13 promoter activity, albeit already weak activity, and exhibits decreased Sp1 transcription factor binding in gel shift assays. ${ }^{43}$

\subsection{2 | Inflammation}

Inflammation plays a key role in AAA development, and several studies have shown that CD4+ $T$ cells accumulate within the aneurysm wall. ${ }^{44}$ These cells secrete inflammatory cytokines that recruit effector cells to the aneurysm site to promote the inflammatory-mediated process. SNPs associated with AAAs in the human population have been identified in several genes that encode some of these key inflammatory components. For example, Bown et al showed that the rs1800896 major (A) allele in the IL-10 promoter was associated with AAA in two different studies. ${ }^{45,46}$ However, there was no significant association between rs1800896 and AAA when the data was corrected for risk factors known to be associated with AAA (tobacco use, age, peripheral artery disease, and so on). In a separate study of an equally sized Chinese population, the $A$ allele was associated with increased AAA formation (OR, 1.64). ${ }^{47}$

Previous in vitro studies demonstrated that the rs1800896 A (risk) allele is associated with lower IL-10 plasma levels, which supports the idea that the A allele increases AAA risk by decreasing expression of this anti-inflammatory cytokine. ${ }^{46-48}$ However, Bown et al showed the opposite: higher IL-10 levels in patients with the AA genotype after EVAR, which may be explained by a separate process controlling the inflammatory response after surgery. ${ }^{45}$

Several studies also support an association between IL-6 signaling and AAA pathobiology. Patients with AAA have higher circulating IL-6 levels, and these same studies suggest that IL- 6 is secreted from the aneurysm since its level directly correlates with aneurysm surface area. ${ }^{50}$ Second, downstream IL-6 signaling effectors, such as JNK, are activated in AAA samples compared to controls. ${ }^{51}$ Further, metaanalysis of five different studies showed that the rs2228145 minor (C) allele within the IL-6R gene (as well as proxy SNPs rs7529229 and rs4129267) was associated with lower AAA risk (OR, 0.84). ${ }^{49}$ rs2228145 is a nonsynonymous variant located in exon 10 of the IL$6 R$ gene that results in substitution of asparagine for alanine at amino acid position 358, which dampens signaling through IL-6R in lymphoblastoid cells. Furthermore, IL-6R inhibition with MR16-1 reduced aortic diameter in mice compared to an IgG negative control antibody when measured at 6 weeks after $\mathrm{CaCl} 2$ treatment
(AAA diameter $0.92 \mathrm{~mm}$ vs $1.08 \mathrm{~mm}$, respectively). ${ }^{52}$ Additionally, angiotensin II-induced AAA formation was reduced in Apo E -/- mice by inhibiting the IL-6 effector JAK with SP600125, providing further evidence that the IL-6 pathway modules aneurysm formation. ${ }^{53,54}$

Finally, rs10757278 (G variant) is located within the 9p21 locus encoding CDKN2A/B and is thought to influence cardiovascular disease risk through an inflammatory-mediated process. ${ }^{55}$ Although this locus has a well-established link to coronary artery disease, myocardial infarction, and type 2 diabetes, the association with AAA was independent of these. ${ }^{56,57}$ Finally, rs10757278 is also associated with peripheral artery disease and intracranial aneurysm, but the strongest association is with AAA (OR, 1.32). ${ }^{58}$

\subsection{3 | Lipid metabolism and cell survival}

Hyperlipidemia is a major risk factor for atherosclerosis, which is found in many patients with AAAs. ${ }^{59}$ Not surprisingly, several DNA variants affecting lipid metabolism influence AAA risk. One of these, rs6511720, is located within the first intron of the LDLR gene and was identified in a large GWAS of UK, New Zealand, and Australian populations. ${ }^{60}$ The rs6511720 minor (A) allele, which is associated with decreased risk of AAA, is located within a DNasehypersensitivity site (DHS) marked by $\mathrm{H} 3 \mathrm{~K} 27$ acetylation in multiple cell types (UCSC Genome Browser). DHS are areas of open chromatin that are accessible to key transcription factors and, along with $\mathrm{H} 3 \mathrm{~K} 27$ acetylation, often mark key promoter and enhancer regions that drive gene expression. ${ }^{61,62}$ Thus, given its location in a putative regulatory region, rs6511720 may lead to allele-specific changes in LDLR gene transcription, although mechanistic studies testing this are necessary. Changes in LDLR expression likely underlie AAA risk, especially given that the LDLR knockout mouse develops AAA. ${ }^{63}$

The rs1466535 major (C) allele, located in the second intron of the LRP1 gene, is associated with increased AAA risk. ${ }^{64-66}$ Aortic tissues from patients harboring the rs1466535 major (C) allele had increased LRP1 expression compared to the minor ( $T$ ) allele, and the $C$ allele exhibited increased transcription activity and increased SREBP-1 binding compared to the T allele. ${ }^{67}$ Interestingly, LRP1 is a large endocytic transmembrane receptor that structurally resembles the LDL binding domains of LDLR, and several studies indicate that LRP1 plays a protective role against AAA formation. ${ }^{68}$ First, selective LRP1 knockout in vascular smooth muscle cells promotes AAA formation in mice. ${ }^{69}$ Second, LRP1 limits protease activity thereby preventing elastin fiber degradation in the vessel wall. ${ }^{70,71}$ While Bown et al found that LRP1 expression was higher for the CC (risk) genotype compared to TT (control) genotype, another much smaller study in Chinese patients found that LRP1 expression is lower in AAA tissue compared to healthy tissue. ${ }^{67,72}$ These conflicting results may be due to differences in sample collection or may represent time-dependent differences in LRP1 expression.

Finally, rs7025486 is located in the first intron of the DAB2IP gene, and the A allele is associated with increased AAA risk. ${ }^{73}$ DAB2IP is expressed in several tissues including heart, endothelium, vascular smooth muscle, as well as several cancer cell lines, and is a member of 
the RasGAP family of proteins critical for TNF-induced ASK1/JNK activation. $^{74,75}$ DAB2IP inhibits cell survival and proliferation by downregulating PI3K-Akt and Ras signaling pathways, ultimately leading to increased apoptosis. ${ }^{76}$ Another, yet less-studied, function of DAB2IP is its ability to regulate lipid droplet metabolism by inhibiting the activity of the lipid trafficking protein, RAB40C. ${ }^{77}$ RAB40C is required for lipid droplet metabolism, since CRISPR-Cas9-mediated deletion of RAB40C causes lipid over-accumulation, while RAB40C overexpression reduces lipid droplet accumulation in hepatocytes. However, in the presence of DAB2IP, RAB40C's effects on lipid processing are reduced. Notably, rs7025486 genotype demonstrates tissue-specific effects on DAB2IP expression. ${ }^{73}$

\subsection{4 $\quad$ Cell adhesion}

Another AAA-associated SNP, rs7635818, is located approximately $200 \mathrm{~kb}$ upstream of the CNTN3 transcription start site. ${ }^{78}$ The CNTN3 gene encodes contactin-3, which is a lipid-anchored cell adhesion protein expressed in aortic tissue. While the contactin family has been extensively studied in the nervous system, only one study to date has examined contactin-3 specifically. ${ }^{79,80}$ The $C$ minor allele is associated with increased AAA risk and shows an even stronger association with $A A A$ in smokers compared to nonsmokers (OR, 1.80 vs 1.56 , respectively). ${ }^{80}$ Given its location in the $5^{\prime}$ proximal gene region, rs7635818 may effect CNTN3 transcription; however, no studies to date have examined the relationship between rs7635818 genotype and CNTN3 expression.

\subsection{5 | Vascular development and EC/SMC differentiation}

rs1795061 is located about $40 \mathrm{~kb}$ upstream of the SMYD2 transcription start site and also associated with AAA. ${ }^{32}$ Transcription factor binding sites have been identified within the SMYD2 eQTL locus, indicating that other SNPs in linkage with rs1795061 may affect transcription factor binding and SMYD2 expression. ${ }^{81}$ The SMYD proteins are a family of lysine methyltransferases that play fundamental roles in regulating skeletal and cardiac morphogenesis. ${ }^{82}$ One member of this family, SMYD2, methylates several histone and nonhistone targets, including BMPR2, Hsp90, and p53. ${ }^{83-85}$ SMYD2 has been implicated in cancer cell proliferation and plays a role in embryonic stem cell differentiation. ${ }^{86,87} \mathrm{New}$ evidence suggests that SMYD2 make be linked to AAA pathogenesis. In particular, one report identified several hypomethylated $\mathrm{CpG}$ islands within the SMYD2 promoter in AAA samples, which had decreased SMYD2 expression compared to healthy control samples. ${ }^{88}$ Whether or not rs1795061 or alternate SNPs in this same locus affect DNA methylation is yet to be determined. However, this is an attractive hypothesis since decreased SMYD2 expression has been described in cardiovascular disease and inflammation. ${ }^{89}$

The same study by Jones et al. identified the AAA-risk variant, rs2836411, which is located at 21q22.2 in an intronic region within the ERG gene. ${ }^{32}$ The rs2836411 minor $(T)$ allele is associated with increased
AAA risk in several populations. ERG is a transcription factor expressed in both hematopoietic and endothelial cells and mediates several key processes of vascular development, including endothelial specification, angiogenesis, and vessel stability. ${ }^{90}$ Not surprisingly, ERG is most highly expressed in arterial tissues, as listed in the GTEx database, and it is an important upstream regulator of VEGF-inducible genes essential for angiogenesis and vasculogenesis. ${ }^{91}$ One potential mechanism linking ERG to AAA formation is the observation that angiogenesis is increased in the aneurysm wall. ${ }^{92}$ Furthermore, ERG binding to a critical regulatory enhancer in the DLL4 gene mediates arterial specification. ${ }^{93}$ Future studies should determine if ERG expression, rs2836411 genotype, and AAA risk are all associated with each other.

\subsection{6 | Additional variants in genes with unknown function}

The rs9316871 (G) minor allele is protective against AAA. ${ }^{32}$ Interestingly, the closest nearby gene to rs9316871 is LINC00540, which is a long noncoding RNA (IncRNA) with no known function to date. However, Jones et al found that this variant was associated with another nearby gene, FGF9, the expression of which was increased in AAA tissue relative to controls. ${ }^{94}$ Briefly, FGF9 is a mitogen secreted from bone marrow cells that exerts several functions on vascular SMC, including stimulating SMC investment of angiogenic vessels as well as driving SMC proliferation after arterial injury. ${ }^{94,95}$ Although allelespecific differences in FGF9 expression may link rs9316871 to AAA risk, it is also possible that this SNP locus affects LINC00540 levels, perhaps through altering its stabilization since the variant is located near the 3' UTR of LINC00540. While these are tempting hypothesis, it is important to emphasize that SNP proximity does not necessarily predict a functional association on nearby genes. Alternative explanations include linkage of rs9316871 with functional SNP(s) elsewhere in the genome or perhaps rs9316871 affects gene architecture via long-range interactions with other gene regions.

\section{3 | LIMITATIONS OF GWAS}

Although excellent tools for identifying variants implicated in disease, GWAS have several limitations that should be kept in mind in order to put these results in the appropriate clinical context. First, given the high number of individual variants being tested, the possibility that an association is actually due to chance is quite high. Second, not all variants identified are causal and it can take great effort to identify functional SNPs. GWAS also fail to capture epistasis between loci, or to what degree interactions between several variants or gene regions influence disease. One of the biggest arguments is that GWAS have limited clinical predictive value and applicability. The latter is due to both the small effect sizes and heritability of the majority of associations, which could be offset easily by environmental contributions. While one hope of GWAS is to identify individuals at risk for disease, this is not as valuable if no personalized treatment exists. Additionally, many of the GWAS-related 
SNPs are at such low allele frequencies that large numbers of individuals would need to be tested to identify a single rare variant, calling into question the practicality of such a test for screening purposes. Finally, except for rare instances, the exact relationship between the vast majority of GWAS associations and AAA risk remains unclear, and relatively very few associations out of all identified are actually causal.

\section{4 | EPIGENETIC REGULATION OF AAAS}

While AAA pathogenesis is influenced by genetic mutations, a number of epigenetic factors also affect aneurysm formation. Epigenetic mechanisms cause dysregulated expression of aneurysm genes without significant sequence variation, as is the case for genetic causes of disease. Epigenetic modes of regulation include microRNAs, long noncoding RNAs, histone modifications, and DNA methylation, all of which modulate gene transcription (Figure 1). Several of these epigenetic changes have an established role in AAA pathogenesis; however, in most cases the connection between epigenetic regulation and aneurysm development is less clear. While genetic and epigenetic mechanisms are discussed separately, the two may interact to facilitate higher order gene regulation. In other words, are the epigenetic factors identified independent of SNPs that affect expression of known aneurysm genes? This is an important question not addressed by most epigenetic studies or GWAS that should be considered in the context of the discussions throughout this manuscript.

\subsection{NONCODING RNAs ASSOCIATED WITH AAAs}

\subsection{1 | MicroRNAs}

MicroRNAs (miRNAs) are short, single-stranded RNA molecules comprised of 17 to 23 bases that exert a variety of cellular functions by directly regulating gene expression. ${ }^{96,97}$ In general, miRNAs negatively regulate gene expression either by degrading mRNA or inhibiting translation. In either case, the mature miRNA pairs with a highly conserved "seed" sequence within the $3^{\prime}$ UTR of the target gene. Importantly, a single miRNA may regulate several genes; thus, most miRNAs are involved in complex regulatory networks of gene expression. ${ }^{98}$ Several miRNAs play a role in AAA development pathogenesis. By far, the miRNA-29 family has one of the strongest associations with AAA, and different studies show that miRNA-29 promotes AAA formation by modulating the fibrotic response and ECM in vitro and in vivo. ${ }^{99}$ Validated targets of miRNA-29b include several collagen types in aorta including COL1A1, COL2A1, COL3A1, and COL5A1. ${ }^{100,101}$

miRNA-29 also targets ECM genes, ELN and FBN1, and members of the MMP family. ${ }^{101,102}$ Maegdefessel et al found that miRNA-29b overexpression enhanced aneurysm expansion and rupture rate, which was also associated with decreased expression of fibrotic genes, including COL1A1, COL3A1, and ELN. ${ }^{99}$ Conversely, inhibiting miRNA-29b with anti-miR-29b decreased AAA rate and increased fibrotic gene expression. Finally, miRNA-29b levels are downregulated at different timepoints throughout AAA development in mice and associated with increased aortic collagen gene expression-protective changes thought to limit AAA expansion. ${ }^{99}$

Another miRNA that appears to affect AAA development by regulating ECM turnover is miR-181b. miR-181b stimulates ECM degradation by inhibiting TIMP3, which normally prevents ECM breakdown. ${ }^{103}$ Accordingly, miR-181b antagonism inhibits ECM remodeling and AAA formation. However, miR-181b has positive and negative effects on atherosclerosis, which makes attempt at therapy challenging since anti-miR targeting could lead to off-target effects. TIMP3 expression is also negatively regulated by miR-205, which leads to decreased ECM breakdown by directly targeting TIMP3. ${ }^{104}$ With less ECM degradation, miR-205 would hypothetically stabilize the aneurysm. Similarly, miR-195 regulates ECM dynamics by directly targeting ECM and MMP-related genes. ${ }^{105}$ Interestingly, miR-195 is

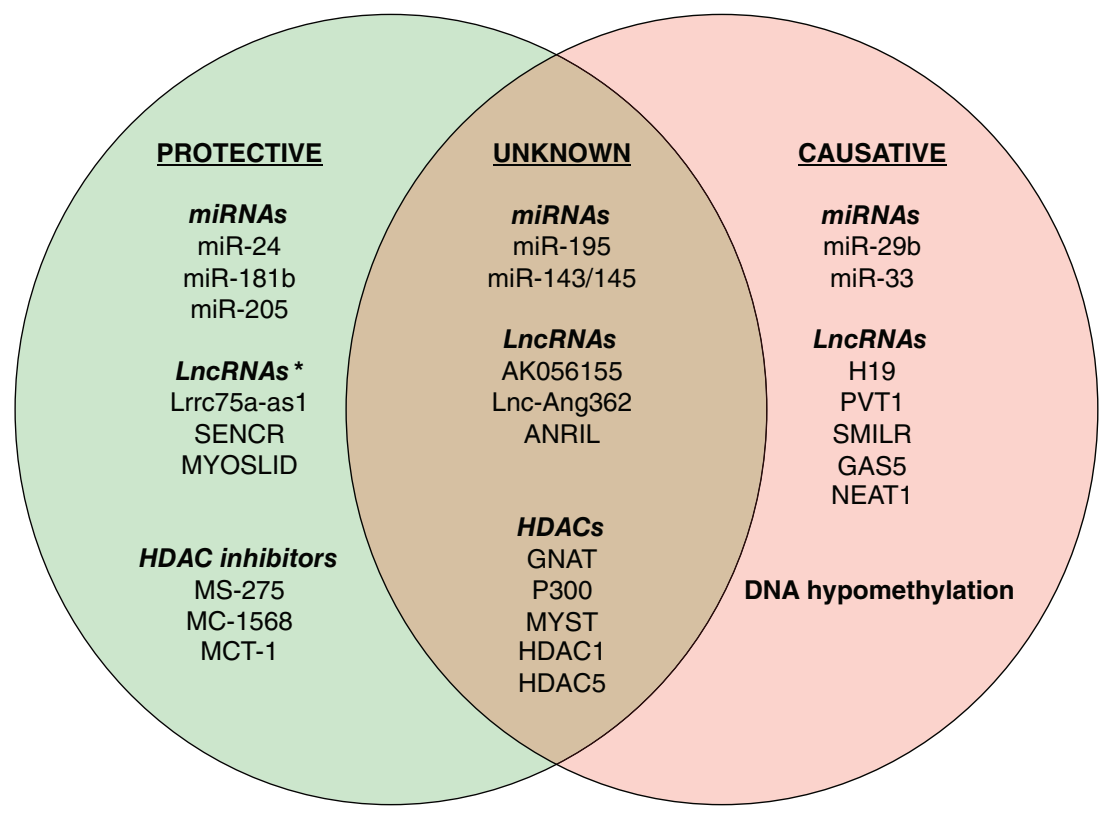

FIGURE 1 Epigenetic factors including noncoding RNAs, histone modifying agents, and changes in DNA methylation associated with AAA. * Most LncRNAs described in this review have not been validated as either protective or causative in relation to AAA. Therefore, the associations listed for LncRNAs in the above diagram are hypothesized based on their reported effect 
reduced in AAA samples but increased in a preclinical mouse model of AAA.

Several miRNAs affect AAA development by modulating different inflammatory components. First, by directly targeting Chi311, miR-24 limits inflammation by inhibiting macrophage recruitment and survival as well as blocking production of cytokines IL-8 and CCL2 by SMCs and macrophages. ${ }^{106}$ Another important microRNA, miR-33, modulates the inflammatory response, but does so by inhibiting the pro-inflammatory cholesterol transporter $A B C A 1 .{ }^{107}$ In both the $\mathrm{CaCl} 2$ and Ang II mouse models of $A A A$, inhibiting miR33 prevents AAA formation through upregulated ABCA1 expression. Global loss of function experiments as well as macrophagespecific deletion of miR-33 both inhibited atherogenesis and related-sequelae, suggesting that the effects of miR-33 on AAAs are mediated by macrophages.

Next, the miRNA-143/145 cluster has been implicated in vascular smooth muscle biology, and in particular, induces a differentiated, contractile smooth muscle cell phenotype. ${ }^{108}$ While studies are lacking regarding the exact effect of this miRNA cluster on aneurysm pathophysiology, it is reasonable to hypothesize it may stabilize the AAA since it inhibits SMC phenotypic modulation, which often occurs during AAA expansion. However, as noted, this miRNA set has been implicated in other vascular diseases and is not specific for AAA.

\subsection{2 | Long noncoding RNAs}

Overall less is known about the exact mechanisms by which long noncoding RNAs (IncRNAs) regulate gene expression compared to miRNAs, especially in the setting of AAAs. LncRNAs are $>200$ nucleotides in length and regulate gene expression by affecting overall gene architecture, specifically by acting as scaffolds for gene regions and transcription factors. In this manner, IncRNAs can guide activator and repressor transcriptional complexes to key regulatory gene regions to modulate overall gene transcription. LncRNAs can also sponge cytoplasmic miRNAs to inhibit their function on transcription. One of the first AAA-associated IncRNAs identified was $\mathrm{H} 19$, which was upregulated in Ang II- and pancreatic elastase mouse models of AAAs compared controls. ${ }^{109}$ In this same study, inhibiting $\mathrm{H} 19$ prevented AAA growth in both described models, indicating that $\mathrm{H} 19$ played a positive role in aneurysm pathogenesis. In support of this, $\mathrm{H} 19$ was upregulated in human AAA and seems to promote aneurysm development by increasing vascular inflammation. ${ }^{110}$

Another IncRNA that has been implicated in AAA pathogenesis is PVT1, which appears to enhance AAA formation. ${ }^{111}$ PVT1 levels are upregulated in AAA tissues from patients as well as from ApoE -/mice infused with Ang II, and stimulation of vascular smooth muscle cells with Ang II in vitro increased PVT1 expression. Overexpression of PVT1 in Ang II-infused mice enhanced vascular smooth muscle cell apoptosis, ECM degradation (as measured by increased MMP-2 and MMP-9 expression), and phenotypic switching of smooth muscle cells (decreased expression of smooth muscle alpha-actin). Further, both PVT1 knockdown in vitro and silencing PVT1 in vivo using lentiviruses blocked these biochemical effects of aneurysm pathogenesis, providing strong evidence that PVT1 promotes AAA formation.

Initially identified as a long noncoding RNA in LDS patients, AK056155 is increased nearly 2-fold in patients with AAAs compared to controls. ${ }^{112}$ Further, since variants in several components of the TGF $\beta$ pathway underlie AAA formation found in LDS, the authors of this study tested the relationship between TGF $\beta$ and AK056155. Interestingly, TGF $\beta$ increased AK056155 expression in a dose-dependent manner, an effect that was found to be downstream of PI3K/AKT signaling. This latter finding is important because AK056155 expression was increased by the PI3K inhibitor, LY294002, highlighting the therapeutic potential of modulating AK056155 levels in the treatment of AAAs.

Several IncRNAs that affect SMC function and differentiation have been identified, and it is reasonable that some of these may also regulate $A A A$ formation since $S M C$ physiology is perturbed in AAAs. ${ }^{113}$ One of the first studies to characterize such IncRNAs was by Leung et al, who identified 29 vascular SMC-enriched IncRNAs that were associated with transcriptionally active chromatin and also differentially regulated by Ang II. ${ }^{114,115}$ One of these, Inc-Ang362, is increased in response to Ang II stimulation and is physically located close to the Ang II-responsive miRNA genes, mir-221 and mir-222, which upregulate $\mathrm{VSMC}$ proliferation and neointimal hyperplasia. ${ }^{116}$ Additionally, very recently, Jeong et al found that the long noncoding RNA Lrrc75a-as1 was enriched in vascular SMC and inhibited vascular calcification, a well-known feature of AAAs. ${ }^{117}$

SMILR was identified in a screen of IncRNAs whose expression was influenced by IL-1alpha and PDGF, cytokines that regulate VSMC migration and proliferation. ${ }^{118}$ SMILR knockdown reduced vSMC proliferation, and its expression was increased in unstable atherosclerotic plaques from human patients. Another IncRNA, SENCR, is enriched in vascular endothelial and smooth muscle cells and inhibits expression of migratory genes while upregulating expression of contractile genes (eg, myocardin) required for SMC differentiation. ${ }^{119}$ Finally, GAS5 inhibits TGF $\beta /$ Smad3-dependent SMC differentiation by scavenging Smad3 via Smad binding elements within the RNA strand. ${ }^{120}$ Thus, based on its ability to downregulate $S M C$ differentiation, it is reasonable to hypothesize that this IncRNA promotes AAA pathogenesis.

The transcription factor myocardin is a potent regulator of SMC gene expression. In an attempt to identify IncRNAs involved in regulating myocardin-induced SMC differentiation, Zhao et al. performed RNA sequencing in human coronary SMC overexpressing myocardin and found that one IncRNA in particular, which they termed MYOSLID, was activated by myocardin. ${ }^{121}$ Specifically, MYOSLID was a direct target of myocardin and SRF, and functional experiments revealed that MYOSLID promoted the mature smooth muscle phenotype and SMC differentiation. Opposite to the effect of MYOSLID, the recently identified NEAT1 promotes the immature, proliferative SMC phenotype, while inhibiting expression of mature, contractile genes by sponging the chromatin modifier WDR5 from key SMC gene loci. ${ }^{122}$ Further, NEAT1 knockout mice displayed decreased neointima formation after vascular injury. As described earlier, the 9p21 genetic risk locus is associated with several vascular diseases, including AAA. ${ }^{64}$ 
While this locus spans several genes, one of the risk polymorphisms is located in the ANRIL gene, which encodes a long noncoding RNA that has been implicated in AAA development. ANRIL is transcribed antisense to the genes CDKN2A and CDKN2B, and several studies indicate that ANRIL modulates SMC proliferation by regulating expression of these genes. ${ }^{123}$

\subsection{Histone modifications}

Histone modifications at key promoter and enhancer gene regions are associated with gene activation or repression, depending on the specific histone signature, and histone acetylases, deacetylases, and methyltransferases all carry out these modifications. H3K4me3 marks active promoters, $\mathrm{H} 3 \mathrm{~K} 4 \mathrm{me} 1$ active enhancers, and H3K27ac marks both active promoters and enhancers. In contrast, H3K27me3 is found at sites of inactive chromatin. Combinations of these histone marks lead to changes in chromatin structure that either facilitates or prevents key transcription factor binding, thereby activating or repressing gene transcription. Furthermore, unique histone signatures distinguish diseased vs healthy tissues. ${ }^{124,125}$

Recently, it has been hypothesized that these epigenetic modifications may also underlie AAA pathogenesis. For example, acetylation of H3K9, H3K14, and H3K18 was increased in AAAs compared to healthy samples. ${ }^{126}$ In a different study, expression of several histone deacetylases (HDAC) was increased in samples from AAA compared to healthy donors, and Ang II infused ApoE -/- AAA mouse models also had higher HDAC expression than controls. ${ }^{127}$ Interestingly, in this same study, class I and Ila HDAC inhibition with MS-275 and MC-1568, respectively, improved survival and decreased AAA formation in mice, which was shown in part to be due to decreased MMP-2 and -9 activity after HDAC inhibition. This is not the first report of HDAC inhibition reducing AAA pathogenesis: another HDAC inhibitor, MCT-1, reduced AAA incidence in Ang II infused Apo E -/mice. ${ }^{128}$ Furthermore, MCT-1 reduced expression of MMP-2 in vSMCs and both MMP-2 and MMP-9 in aortic tissue. These aforementioned studies suggest that histone acetylation patterns located within the MMP-2 and MMP-9 genes modulate AAA formation, and that targeting histone acetylation at these specific loci may limit AAA expansion.

Histone modifications in immune cells module AAA pathogenesis; however, the specific direction of effect is less understood. Expression of histone acetyltransferases including GNAT, p300, and MYST was significantly higher in T cells and endothelial cells from AAA vs healthy tissue samples. ${ }^{126}$ However, HDAC1 mRNA levels were lower in $\mathrm{T}$ cells collected from patients with AAA compared to controls, while $\mathrm{H} 3$ and $\mathrm{H} 3 \mathrm{~K} 14$ acetylation in T cells was higher than in controls. ${ }^{129}$ This is in contrast to findings from a different group, who showed that HDAC1 and HDAC5 mRNA levels were higher in T regulatory cells collected from patients with AAA vs controls. ${ }^{130}$ One possible explanation for this finding is that levels of acetylation and HDAC expression change throughout the course of disease. Another possibility is that $T$ regulatory cells as a subset may be marked by unique histone acetylation patterns that do not reflect the larger peripheral $\mathrm{T}$ cell population.

\section{3 | DNA methylation}

DNA methylation is a heritable epigenetic modification that occurs at $\mathrm{CpG}$ islands within gene promoters, resulting in transcriptional silencing, and is carried out on cytosines by DNA methyltransferases (DNMTs). While the largest effect of DNA methylation on AAA risk is due to transcriptional dysregulation of key aneurysm-associated genes, few studies actually implicate AAA genes as targets. One explanation for this could be decreased sensitivity of current panels or exclusion of some of these genes on existing panels. Additionally, it is possible that DNA methylation is a sensitive epigenetic change that is not recapitulated completely by current models. Finally, analysis of vascular cell types including endothelial, smooth muscle, or adventitial cells may yield more aneurysm-specific targets, since the studies that do exist have focused on DNA methylation in T cells. Increasing evidence suggests that $T$ cell dysfunction, particularly decreased suppressive effects of CD4 + CD25+ T regulatory cells, drives AAA development. ${ }^{131}$ Part of this change arises from epigenetic alterations like DNA methylation, which is significantly decreased in T cells from patients with AAA compared to healthy controls. ${ }^{132}$ Similarly, DNA methylation in T cells was negatively correlated with AAA diameter. Expression of both DNMT1 and methyl-CpG-binding domain 2 (MBD2), both involved in mediating DNA methylation and transcriptional repression, was also decreased in isolated $T$ cells from AAA samples relative to controls. In contrast, $X i a$ et al showed that T regulatory cells from AAA patients have higher levels of DNMT1, DNMT3A, and MBD2 compared to controls. ${ }^{130}$

Elevated homocysteine levels have long been associated with vascular disease, and its relation to AAA has also been reported previously. ${ }^{133,134}$ Additionally, several DNA variants within genes involved in homocysteine metabolism have been linked to AAA and/or aortic diameter in the human population. These include rs8003379 in MTHFD1, rs326118 in MTRR, rs202680 in FOLH1, rs2853523 in MTR, and rs1801133 and c.677C > T in MTHFR. ${ }^{135,136}$ It has been suggested that hyperhomocysteinemia may underlie AAA development through cell type-specific hypomethylation. ${ }^{137}$ However, more studies are needed to test this hypothesis directly.

While DNA hypomethylation is associated with AAA, as noted above, several additional studies indicate that hypermethylation at specific gene promoters is also linked with AAA development. One recent study addressed this by assessing global methylation in peripheral blood mononuclear cells from patients with AAA and compared these methylation patterns to healthy controls. ${ }^{88}$ This study showed that AAA DNA was hypermethylated and correlated with aneurysm size. Specific CpG sites of hypermethylation occurred in IL6R and ERG, while CpG hypomethylation was found in SERPINB9 and SMYD2. Further, methylation of the SMYD2 promoter was directly correlated with SMYD2 expression, which was decreased in AAA 
samples. From this study and others, it is clear that unique DNA methylation patterns across multiple genes influence AAA risk.

\section{5 | CONCLUSION}

Numerous genetic and epigenetic factors may influence AAA risk. In addition to Mendelian, single-gene causes, numerous DNA variants (the majority of which are in noncoding regions) with a potential link to AAA in humans have been identified in GWAS and are outlined here. Importantly, most GWAS SNPs do not affect AAA risk, and these should be differentiated from the more rare, true pathogenic variants. Accordingly, it is necessary to determine which SNPs out of the many identified are functional variants. Coding variants can affect protein function while others in promoter-enhancers may affect gene expression, and such changes in protein activity or transcription, respectively, modify AAA risk. In vitro and in vivo experiments are required to determine if the variants described above are functional. GWAS for AAA have identified SNPs in genes with previously unknown function. In an effort to identify how such variants affect AAA risk, studies have helped uncover how gene function regulates AAA pathogenesis. Future research should be geared toward cell type-specific mechanisms of disease, since a significant number of reports analyze whole aortic tissue rather than specific cell types from aneurysm samples.

Several microRNAs and long noncoding RNAs have been identified that regulate expression of aneurysm-related genes and play a role in AAA pathogenesis. Accordingly, some of these noncoding RNAs may serve as therapeutic targets for decreasing AAA progression. Similarly, dynamic chromatin states regulate expression of genes known to play a role in aneurysm development. Such functional states are also modulated by histone modifications and DNA methylations, which vary in AAA, and additional work should focus on the specific gene loci where these modifications occur.

\section{CONFLICT OF INTEREST}

The authors declare no conflict of interest.

\section{DATA AVAILABILITY STATEMENT}

Data sharing is not applicable to this article as no new data were created or analyzed in this study.

\section{ORCID}

Kevin D. Mangum (D) https://orcid.org/0000-0003-2838-7094

\section{REFERENCES}

1. Nordon IM, Hinchliffe RJ, Loftus IM, Thompson MM. Pathophysiology and epidemiology of abdominal aortic aneurysms. Nat Rev Cardiol. 2011;8(2):92-102.

2. Karthikesalingam A, Vidal-Diez A, Holt PJ et al. Thresholds for abdominal aortic aneurysm repair in England and the United States. N Engl J Med. 2016;375(21):2051-2059.

3. Altobelli E, Rapacchietta L, Profeta VF, Fagnano R. Risk factors for abdominal aortic aneurysm in population-based studies: a systematic review and meta-analysis. Int $J$ Environ Res Public Health. 2018;15(12):1-19.

4. Aune D, Schlesinger S, Norat T, Riboli E. Tobacco smoking and the risk of abdominal aortic aneurysm: a systematic review and metaanalysis of prospective studies. Sci Rep. 2018;8(1):14786.

5. Sakalihasan N, Michel JB, Katsargyris A et al. Abdominal aortic aneurysms. Nat Rev Dis Primers. 2018;4(1):34.

6. Joergensen TM, Christensen K, Lindholt JS, Larsen LA, Green A, Houlind K. Editor's choice-high heritability of liability to abdominal aortic aneurysms: a population based twin study. Eur J Vasc Endovasc Surg. 2016;52(1):41-46.

7. Boese AC, Chang L, Yin KJ, Chen YE, Lee JP, Hamblin MH. Sex differences in abdominal aortic aneurysms. Am J Physiol Heart Circ Physiol. 2018;314(6):H1137-H1152.

8. Lo RC, Bensley RP, Hamdan AD et al. Gender differences in abdominal aortic aneurysm presentation, repair, and mortality in the vascular study Group of new England. J Vasc Surg. 2013;57(5):1261-1268.

9. Deery SE, Schermerhorn ML. Should abdominal aortic aneurysms in women be repaired at a lower diameter threshold? Vasc Endovascular Surg. 2018;52(7):543-547.

10. van de Luijtgaarden KM, Rouwet EV, Hoeks SE, Stolker RJ, Verhagen HJ, Majoor-Krakauer D. Risk of abdominal aortic aneurysm (AAA) among male and female relatives of AAA patients. Vasc Med. 2017;22(2):112-118.

11. Lo RC, Lu B, Fokkema MT et al. Relative importance of aneurysm diameter and body size for predicting abdominal aortic aneurysm rupture in men and women. J Vasc Surg. 2014;59(5):1209-1216.

12. Kumar Y, Hooda K, Li S, Goyal P, Gupta N, Adeb M. Abdominal aortic aneurysm: pictorial review of common appearances and complications. Ann Transl Med. 2017;5(12):256.

13. Barrett $\mathrm{HE}$, Cunnane EM, Hidayat $\mathrm{H}$ et al. On the influence of wall calcification and intraluminal thrombus on prediction of abdominal aortic aneurysm rupture. J Vasc Surg. 2018;67(4):1234-1246.e2.

14. Haller SJ, Crawford JD, Courchaine KM et al. Intraluminal thrombus is associated with early rupture of abdominal aortic aneurysm. J Vasc Surg. 2018;67(4):1051-1058.e1.

15. Fillinger MF, Raghavan ML, Marra SP, Cronenwett JL, Kennedy FE. In vivo analysis of mechanical wall stress and abdominal aortic aneurysm rupture risk. J Vasc Surg. 2002;36(3):589-597.

16. Aoki C, Fukuda W, Kondo $\mathrm{N}$ et al. Surgical management of mycotic aortic aneurysms. Ann Vasc Dis. 2017;10(1):29-35.

17. Bednarkiewicz $M$, Pretre R, Kalangos A, Khatchatourian G, Bruschweiler I, Faidutti B. Aortocaval fistula associated with abdominal aortic aneurysm: a diagnostic challenge. Ann Vasc Surg. 1997;11 (5):464-466.

18. Derubertis BG, Trocciola SM, Ryer EJ et al. Abdominal aortic aneurysm in women: prevalence, risk factors, and implications for screening. J Vasc Surg. 2007;46(4):630-635.

19. Antoniou GA, Georgiadis GS, Antoniou SA, Kuhan G, Murray D. A meta-analysis of outcomes of endovascular abdominal aortic aneurysm repair in patients with hostile and friendly neck anatomy. J Vasc Surg. 2013;57(2):527-538.

20. Bischoff MS, Peters AS, Meisenbacher K, Böckler D. Challenging access in endovascular repair of infrarenal aortic aneurysms. J Cardiovasc Surg (Torino). 2014;55(2 Suppl 1):75-83.

21. Etkin Y, Baig A, Foley PJ et al. Management of difficult access during endovascular aneurysm repair. Ann Vasc Surg. 2017;44:77-82.

22. Caglayan AO, Dundar M. Inherited diseases and syndromes leading to aortic aneurysms and dissections. Eur J Cardiothorac Surg. 2009; 35(6):931-940.

23. Franken $R$, Radonic $T$, den Hartog $A W$ et al. The revised role of TGF- $\beta$ in aortic aneurysms in Marfan syndrome. Neth Heart J. 2015; 23(2):116-121.

24. Benke K, Ágg B, Szilveszter B et al. The role of transforming growth factor-beta in Marfan syndrome. Cardiol J. 2013;20(3):227-234. 
25. Romaniello F, Mazzaglia D, Pellegrino A et al. Aortopathy in Marfan syndrome: an update. Cardiovasc Pathol. 2014;23(5):261-266.

26. Verstraeten A, Alaerts M, Van Laer L, Loeys B. Marfan syndrome and related disorders: 25 years of gene discovery. Hum Mutat. 2016; 37(6):524-531.

27. Van Laer L, Dietz H, Loeys B. Loeys-Dietz syndrome. Adv Exp Med Biol. 2014;802:95-105.

28. Schepers $D$, Tortora $G$, Morisaki $H$ et al. A mutation update on the LDS-associated genes TGFB2/3 and SMAD2/3. Hum Mutat. 2018; 39(5):p621-p634.

29. Brooke BS, Karnik SK, Li DY. Extracellular matrix in vascular morphogenesis and disease: structure versus signal. Trends Cell Biol. 2003;13(1):51-56.

30. Raffetto JD, Khalil RA. Matrix metalloproteinases and their inhibitors in vascular remodeling and vascular disease. Biochem Pharmacol. 2008;75(2):346-359.

31. Saracini C, Bolli P, Sticchi E et al. Polymorphisms of genes involved in extracellular matrix remodeling and abdominal aortic aneurysm. J Vasc Surg. 2012;55(1):171-179.e2.

32. Jones GT, Tromp G, Kuivaniemi $\mathrm{H}$ et al. Meta-analysis of genomewide association studies for abdominal aortic aneurysm identifies four new disease-specific risk loci. Circ Res. 2017;120(2):341-353.

33. Li T, Lv Z, Jing JJ, Yang J, Yuan Y. Matrix metalloproteinase family polymorphisms and the risk of aortic aneurysmal diseases: a systematic review and meta-analysis. Clin Genet. 2018;93(1):15-32.

34. Freestone T, Turner RJ, Coady A, Higman DJ, Greenhalgh RM, Powell JT. Inflammation and matrix metalloproteinases in the enlarging abdominal aortic aneurysm. Arterioscler Thromb Vasc Biol. 1995; 15(8):1145-1151.

35. Davis V, Persidskaia R, Baca-Regen $L$ et al. Matrix metalloproteinase-2 production and its binding to the matrix are increased in abdominal aortic aneurysms. Arterioscler Thromb Vasc Biol. 1998;18(10):1625-1633.

36. Pyo R, Lee JK, Shipley JM et al. Targeted gene disruption of matrix metalloproteinase-9 (gelatinase B) suppresses development of experimental abdominal aortic aneurysms. J Clin Invest. 2000;105 (11):1641-1649.

37. Longo GM, Xiong W, Greiner TC, Zhao Y, Fiotti N, Baxter BT. Matrix metalloproteinases 2 and 9 work in concert to produce aortic aneurysms. J Clin Invest. 2002;110(5):625-632.

38. Price SJ, Greaves DR, Watkins H. Identification of novel, functional genetic variants in the human matrix metalloproteinase-2 gene: role of Sp1 in allele-specific transcriptional regulation. J Biol Chem. 2001; 276(10):7549-7558.

39. Hadi T, Boytard L, Silvestro $M$ et al. Macrophage-derived netrin-1 promotes abdominal aortic aneurysm formation by activating MMP3 in vascular smooth muscle cells. Nat Commun. 2018;9(1):5022.

40. Deguara J, Burnand KG, Berg J et al. An increased frequency of the $5 \mathrm{~A}$ allele in the promoter region of the MMP3 gene is associated with abdominal aortic aneurysms. Hum Mol Genet. 2007;16(24): 3002-3007.

41. Zhu C, Odeberg J, Hamsten A, Eriksson P. Allele-specific MMP-3 transcription under in vivo conditions. Biochem Biophys Res Commun. 2006;348(3):1150-1156.

42. Souslova V, Townsend PA, Mann J et al. Allele-specific regulation of matrix metalloproteinase-3 gene by transcription factor NFkappaB. PLoS One. 2010;5(3):e9902.

43. Shi $M$, Xia J, Xing $H$ et al. The Sp1-mediaded allelic regulation of MMP13 expression by an ESCC susceptibility SNP rs2252070. Sci Rep. 2016;6:27013.

44. Galle $\mathrm{C}$, Schandené L, Stordeur $\mathrm{P}$ et al. Predominance of type 1 CD4 $+\mathrm{T}$ cells in human abdominal aortic aneurysm. Clin Exp Immunol. 2005;142(3):519-527.
45. Bown MJ, Horsburgh T, Nicholson ML, Bell PR, Sayers RD. Cytokine gene polymorphisms and the inflammatory response to abdominal aortic aneurysm repair. Br J Surg. 2003;90(9):1085-1092.

46. Bown MJ, Lloyd GM, Sandford RM et al. The interleukin-10-1082 'A' allele and abdominal aortic aneurysms. J Vasc Surg. 2007;46(4): 687-693.

47. Wang F, Quan QQ, Zhang CL, Li YB, Jiang TB. Association between polymorphisms in the interleukin-10 gene and risk of abdominal aortic aneurysm. Genet Mol Res. 2015;14(4):17599-17604.

48. Eskdale J, Gallagher G, Verweij CL, Keijsers V, Westendorp RG, Huizinga TW. Interleukin 10 secretion in relation to human IL-10 locus haplotypes. Proc Natl Acad Sci U S A. 1998;95(16):9465-9470.

49. Harrison SC, Smith AJ, Jones GT et al. Interleukin-6 receptor pathways in abdominal aortic aneurysm. Eur Heart J. 2013;34(48):37073716.

50. Dawson J, Cockerill GW, Choke E, Belli AM, Loftus I, Thompson MM. Aortic aneurysms secrete interleukin-6 into the circulation. J Vasc Surg. 2007;45(2):350-356.

51. Yoshimura K, Aoki H, lkeda $\mathrm{Y}$ et al. Regression of abdominal aortic aneurysm by inhibition of c-Jun N-terminal kinase. Nat Med. 2005; 11(12):1330-1338.

52. Nishihara $\mathrm{M}$, Aoki $\mathrm{H}$, Ohno $\mathrm{S}$ et al. The role of IL-6 in pathogenesis of abdominal aortic aneurysm in mice. PLoS One. 2017;12(10): e0185923.

53. Yoshimura K, Aoki H, Ikeda Y, Furutani A, Hamano K, Matsuzaki M. Identification of c-Jun $\mathrm{N}$-terminal kinase as a therapeutic target for abdominal aortic aneurysm. Ann N Y Acad Sci. 2006;1085:403-406.

54. Yoshimura K, Aoki H, Ikeda Y, Furutani A, Hamano K, Matsuzaki $M$. Regression of abdominal aortic aneurysm by inhibition of c-Jun N-terminal kinase in mice. Ann N Y Acad Sci. 2006;1085:74-81.

55. Motterle A, Pu X, Wood $\mathrm{H}$ et al. Functional analyses of coronary artery disease associated variation on chromosome 9 p21 in vascular smooth muscle cells. Hum Mol Genet. 2012;21(18):p4021-p4029.

56. Chen Z, Qian Q, Ma G et al. A common variant on chromosome 9 p21 affects the risk of early-onset coronary artery disease. Mol Biol Rep. 2009;36(5):889-893.

57. Helgadottir A, Thorleifsson G, Manolescu A et al. A common variant on chromosome $9 \mathrm{p} 21$ affects the risk of myocardial infarction. Science. 2007;316(5830):1491-1493.

58. Helgadottir A, Thorleifsson G, Magnusson KP et al. The same sequence variant on 9p21 associates with myocardial infarction, abdominal aortic aneurysm and intracranial aneurysm. Nat Genet. 2008;40(2):217-224.

59. Johnsen SH, Forsdahl SH, Singh K, Jacobsen BK. Atherosclerosis in abdominal aortic aneurysms: a causal event or a process running in parallel? The Tromsø study. Arterioscler Thromb Vasc Biol. 2010;30 (6):1263-1268.

60. Bradley DT, Hughes AE, Badger SA et al. A variant in LDLR is associated with abdominal aortic aneurysm. Circ Cardiovasc Genet. 2013;6 (5):498-504.

61. Crawford GE, Holt IE, Mullikin JC et al. Identifying gene regulatory elements by genome-wide recovery of DNase hypersensitive sites. Proc Natl Acad Sci U S A. 2004;101(4):992-997.

62. Kim TK, Shiekhattar R. Architectural and functional commonalities between enhancers and promoters. Cell. 2015;162(5):948-959.

63. Tangirala RK, Rubin EM, Palinski W. Quantitation of atherosclerosis in murine models: correlation between lesions in the aortic origin and in the entire aorta, and differences in the extent of lesions between sexes in LDL receptor-deficient and apolipoprotein Edeficient mice. J Lipid Res. 1995;36(11):2320-2328.

64. Willer CJ, Sanna S, Jackson AU et al. Newly identified loci that influence lipid concentrations and risk of coronary artery disease. Nat Genet. 2008;40(2):161-169. 
65. Aulchenko YS, Ripatti S, Lindqvist I et al. Loci influencing lipid levels and coronary heart disease risk in 16 European population cohorts. Nat Genet. 2009;41(1):47-55.

66. Galora $S$ et al. Association of rs1466535 LRP1 but not rs3019885 SLC30A8 and rs6674171 TDRD10 gene polymorphisms with abdominal aortic aneurysm in Italian patients. J Vasc Surg. 2015;61 (3):787-792.

67. Bown MJ, Jones GT, Harrison SC et al. Abdominal aortic aneurysm is associated with a variant in low-density lipoprotein receptorrelated protein 1. Am J Hum Genet. 2011;89(5):619-627.

68. Lillis AP, Mikhailenko I, Strickland DK. Beyond endocytosis: LRP function in cell migration, proliferation and vascular permeability. J Thromb Haemost. 2005;3(8):1884-1893.

69. Boucher P, Gotthardt M, Li WP, Anderson RG, Herz J. LRP: role in vascular wall integrity and protection from atherosclerosis. Science. 2003;300(5617):329-332.

70. Strickland DK, Au DT, Cunfer P, Muratoglu SC. Low-density lipoprotein receptor-related protein-1: role in the regulation of vascular integrity. Arterioscler Thromb Vasc Biol. 2014;34(3):487-498.

71. Muratoglu SC, Belgrave S, Hampton B et al. LRP1 protects the vasculature by regulating levels of connective tissue growth factor and HtrA1. Arterioscler Thromb Vasc Biol. 2013;33(9):2137-2146.

72. Chan CY, Chan YC, Cheuk BL, Cheng SW. A pilot study on low density lipoprotein receptor-related protein-1 in Chinese patients with abdominal aortic aneurysm. Eur J Vasc Endovasc Surg. 2013;46 (5):549-556.

73. Gretarsdottir S, Baas AF, Thorleifsson G et al. Genome-wide association study identifies a sequence variant within the DAB2IP gene conferring susceptibility to abdominal aortic aneurysm. Nat Genet. 2010;42(8):692-697.

74. Zhang R, He X, Liu W, Lu M, Hsieh JT, Min W. AlP1 mediates TNFalpha-induced ASK1 activation by facilitating dissociation of ASK1 from its inhibitor 14-3-3. J Clin Invest. 2003;111(12):1933-1943.

75. Zhang $H$, Zhang $R$, Luo $Y$, D'Alessio A, Pober JS, Min W. AIP1/DAB2IP, a novel member of the Ras-GAP family, transduces TRAF2-induced ASK1-JNK activation. J Biol Chem. 2004;279 (43):44955-44965.

76. Xie D, Gore C, Zhou J et al. DAB2IP coordinates both PI3K-Akt and ASK1 pathways for cell survival and apoptosis. Proc Natl Acad Sci U S A. 2009;106(47):19878-19883.

77. Luo X, Li C, Tan R et al. A RasGAP, DAB2IP, regulates lipid droplet homeostasis by serving as GAP toward RAB40C. Oncotarget. 2017;8 (49):85415-85427.

78. Elmore JR, Obmann MA, Kuivaniemi $\mathrm{H}$ et al. Identification of a genetic variant associated with abdominal aortic aneurysms on chromosome 3p12.3 by genome wide association. J Vasc Surg. 2009;49 (6):1525-1531.

79. Oguro-Ando A, Zuko A, Kleijer KTE, Burbach JPH. A current view on contactin-4, -5 , and -6 : implications in neurodevelopmental disorders. Mol Cell Neurosci. 2017;81:72-83.

80. Bouyain S, Watkins DJ. The protein tyrosine phosphatases PTPRZ and PTPRG bind to distinct members of the contactin family of neural recognition molecules. Proc Natl Acad Sci U S A. 2010;107(6): 2443-2448.

81. Pahl MC, Erdman R, Kuivaniemi H, Lillvis JH, Elmore JR, Tromp G. Transcriptional (ChIP-Chip) analysis of ELF1, ETS2, RUNX1 and STAT5 in human abdominal aortic aneurysm. Int J Mol Sci. 2015;16 (5):11229-11258.

82. Du SJ, Tan X, Zhang J. SMYD proteins: key regulators in skeletal and cardiac muscle development and function. Anat Rec (Hoboken). 2014;297(9):1650-1662.

83. Huang J, Perez-Burgos L, Placek BJ et al. Repression of p53 activity by Smyd2-mediated methylation. Nature. 2006;444(7119):629-632.

84. Gao S, Wang Z, Wang W et al. The lysine methyltransferase SMYD2 methylates the kinase domain of type II receptor BMPR2 and stimulates bone morphogenetic protein signaling. J Biol Chem. 2017; 292(30):12702-12712.

85. Donlin LT, Andresen C, Just S et al. Smyd2 controls cytoplasmic lysine methylation of Hsp90 and myofilament organization. Genes Dev. 2012;26(2):114-119.

86. Thomenius MJ, Totman J, Harvey D et al. Small molecule inhibitors and CRISPR/Cas9 mutagenesis demonstrate that SMYD2 and SMYD3 activity are dispensable for autonomous cancer cell proliferation. PLoS One. 2018;13(6):e0197372.

87. Sesé B, Barrero MJ, Fabregat MC, Sander V, Izpisua Belmonte JC. SMYD2 is induced during cell differentiation and participates in early development. Int J Dev Biol. 2013;57(5):357-364.

88. Toghill BJ, Saratzis A, Freeman PJ, Sylvius N, UKAGS collaborators, Bown MJ. SMYD2 promoter DNA methylation is associated with abdominal aortic aneurysm (AAA) and SMYD2 expression in vascular smooth muscle cells. Clin Epigenetics. 2018;10:29.

89. Xu G, Liu G, Xiong S, Liu H, Chen X, Zheng B. The histone methyltransferase Smyd2 is a negative regulator of macrophage activation by suppressing interleukin 6 (IL-6) and tumor necrosis factor $\alpha$ (TNF-

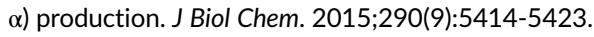

90. Shah AV, Birdsey GM, Randi AM. Regulation of endothelial homeostasis, vascular development and angiogenesis by the transcription factor ERG. Vascul Pharmacol. 2016;86:3-13.

91. Fish JE, Cantu Gutierrez M, Dang LT et al. Dynamic regulation of VEGF-inducible genes by an ERK/ERG/p300 transcriptional network. Development. 2017;144(13):2428-2444.

92. Kaneko H, Anzai T, Takahashi T et al. Role of vascular endothelial growth factor-a in development of abdominal aortic aneurysm. Cardiovasc Res. 2011;91(2):358-367.

93. Wythe JD, Dang LT, Devine WP et al. ETS factors regulate Vegfdependent arterial specification. Dev Cell. 2013;26(1):45-58.

94. Frontini MJ, Nong Z, Gros R et al. Fibroblast growth factor 9 delivery during angiogenesis produces durable, vasoresponsive microvessels wrapped by smooth muscle cells. Nat Biotechnol. 2011;29(5): 421-427.

95. Agrotis A, Kanellakis P, Kostolias G et al. Proliferation of neointimal smooth muscle cells after arterial injury. Dependence on interactions between fibroblast growth factor receptor-2 and fibroblast growth factor-9. J Biol Chem. 2004;279(40):42221-42229.

96. Towler $\mathrm{BP}$, Jones $\mathrm{Cl}$, Newbury SF. Mechanisms of regulation of mature miRNAs. Biochem Soc Trans. 2015;43(6):1208-1214.

97. Bartel DP. MicroRNAs: target recognition and regulatory functions. Cell. 2009;136(2):215-233.

98. Zafari S, Backes C, Leidinger P, Meese E, Keller A. Regulatory microRNA networks: complex patterns of target pathways for diseaserelated and housekeeping microRNAs. Genomics Proteomics Bioinformatics. 2015;13(3):159-168.

99. Maegdefessel L, Azuma J, Toh R et al. Inhibition of microRNA-29b reduces murine abdominal aortic aneurysm development. J Clin Invest. 2012;122(2):497-506.

100. Maegdefessel L, Azuma J, Tsao PS. MicroRNA-29b regulation of abdominal aortic aneurysm development. Trends Cardiovasc Med. 2014;24(1):1-6.

101. Boon RA, Seeger T, Heydt S et al. MicroRNA-29 in aortic dilation: implications for aneurysm formation. Circ Res. 2011;109(10):11151119.

102. Chen KC, Wang YS, Hu CY et al. OxLDL up-regulates microRNA29b, leading to epigenetic modifications of MMP-2/MMP-9 genes: a novel mechanism for cardiovascular diseases. Faseb J. 2011;25(5): 1718-1728.

103. Di Gregoli K, Mohamad Anuar NN, Bianco R et al. MicroRNA-181b controls atherosclerosis and aneurysms through regulation of TIMP3 and elastin. Circ Res. 2017;120(1):49-65.

104. Kim CW, Kumar S, Son DJ, Jang IH, Griendling KK, Jo H. Prevention of abdominal aortic aneurysm by anti-microRNA-712 or anti- 
microRNA-205 in angiotensin II-infused mice. Arterioscler Thromb Vasc Biol. 2014;34(7):1412-1421.

105. Zampetaki A, Attia R, Mayr U et al. Role of miR-195 in aortic aneurysmal disease. Circ Res. 2014;115(10):857-866.

106. Maegdefessel L, Spin JM, Raaz U et al. miR-24 limits aortic vascular inflammation and murine abdominal aneurysm development. Nat Commun. 2014;5:5214.

107. Nakao T, Horie T, Baba O et al. Genetic ablation of MicroRNA-33 attenuates inflammation and abdominal aortic aneurysm formation via several anti-inflammatory pathways. Arterioscler Thromb Vasc Biol. 2017;37(11):2161-2170.

108. Rangrez AY, Massy ZA, Metzinger-Le Meuth V, Metzinger L. miR143 and miR-145: molecular keys to switch the phenotype of vascular smooth muscle cells. Circ Cardiovasc Genet. 2011;4(2):197-205.

109. Li DY, Busch A, Jin $\mathrm{H}$ et al. $\mathrm{H} 19$ induces abdominal aortic aneurysm development and progression. Circulation. 2018;138(15):15511568.

110. Sun $\mathrm{Y}$, Zhong L, He $\mathrm{X}$ et al. LncRNA H19 promotes vascular inflammation and abdominal aortic aneurysm formation by functioning as a competing endogenous RNA. J Mol Cell Cardiol. 2019;131:66-81.

111. Zhang Z, Zou G, Chen X et al. Knockdown of IncRNA PVT1 Inhibits Vascular Smooth Muscle Cell Apoptosis and Extracellular Matrix Disruption in a Murine Abdominal Aortic Aneurysm Model. Mol Cells. 2019;42(3):218-227.

112. Yu B, Liu L, Sun $H$, Chen Y. Long noncoding RNA AK056155 involved in the development of Loeys-Dietz syndrome through AKT/PI3K signaling pathway. Int J Clin Exp Pathol. 2015;8(9):1076810775.

113. Li Y, Maegdefessel L. Non-coding RNA contribution to thoracic and abdominal aortic aneurysm disease development and progression. Front Physiol. 2017;8:429.

114. Leung A, Stapleton K, Natarajan R. Functional long non-coding RNAs in vascular smooth muscle cells. Curr Top Microbiol Immunol. 2016;394:127-141.

115. Leung A, Trac C, Jin W et al. Novel long noncoding RNAs are regulated by angiotensin II in vascular smooth muscle cells. Circ Res. 2013;113(3): 266-278.

116. Liu X, Cheng Y, Zhang S, Lin Y, Yang J, Zhang C. A necessary role of miR-221 and miR-222 in vascular smooth muscle cell proliferation and neointimal hyperplasia. Circ Res. 2009;104(4):476-487.

117. Jeong $\mathrm{G}$, Kwon DH, Shin $\mathrm{S}$ et al. Long noncoding RNAs in vascular smooth muscle cells regulate vascular calcification. Sci Rep. 2019;9 (1):5848.

118. Ballantyne MD, Pinel K, Dakin R et al. Smooth muscle enriched long noncoding RNA (SMILR) regulates cell proliferation. Circulation. 2016;133(21):2050-2065.

119. Bell RD, Long $X$, Lin $M$ et al. Identification and initial functional characterization of a human vascular cell-enriched long noncoding RNA Arterioscler Thromb Vasc Biol. 2014;34(6):1249-1259.

120. Tang R, Zhang G, Wang YC, Mei X, Chen SY. The long non-coding RNA GAS5 regulates transforming growth factor $\beta$ (TGF- $\beta$ )-induced smooth muscle cell differentiation via RNA Smad-binding elements. J Biol Chem. 2017;292(34):14270-14278.

121. Zhao J, Zhang W, Lin $M$ et al. MYOSLID is a novel serum response factor-dependent long noncoding RNA that amplifies the vascular smooth muscle differentiation program. Arterioscler Thromb Vasc Biol. 2016;36(10):2088-2099.

122. Ahmed ASI, Dong K, Liu J et al. Long noncoding RNA NEAT1 (nuclear paraspeckle assembly transcript 1) is critical for phenotypic switching of vascular smooth muscle cells. Proc Natl Acad Sci U S A. 2018;115(37):E8660-E8667.

123. Hinterseher I, Tromp G, Kuivaniemi H. Genes and abdominal aortic aneurysm. Ann Vasc Surg. 2011;25(3):388-412.

124. Stratton MS, Farina FM, Elia L. Epigenetics and vascular diseases. J Mol Cell Cardiol. 2019;133:148-163.

125. Whayne TF. Epigenetics in the development, modification, and prevention of cardiovascular disease. Mol Biol Rep. 2015;42(4): 765-776.

126. Han Y, Tanios F, Reeps $C$ et al. Histone acetylation and histone acetyltransferases show significant alterations in human abdominal aortic aneurysm. Clin Epigenetics. 2016;8:3.

127. Galán $M$, Varona $S$, Orriols $M$ et al. Induction of histone deacetylases (HDACs) in human abdominal aortic aneurysm: therapeutic potential of HDAC inhibitors. Dis Model Mech. 2016;9(5): 541-552.

128. Vinh A, Gaspari TA, Liu HB, Dousha LF, Widdop RE, Dear AE. A novel histone deacetylase inhibitor reduces abdominal aortic aneurysm formation in angiotensin II-infused apolipoprotein E-deficient mice. J Vasc Res. 2008;45(2):143-152.

129. Jiang $\mathrm{H}, \mathrm{Xia} \mathrm{Q}$, Xin $\mathrm{S}$ et al. Abnormal epigenetic modifications in peripheral T cells from patients with abdominal aortic aneurysm are correlated with disease development. J Vasc Res. 2015;52(6): 404-413.

130. Xia Q, Zhang J, Han $Y$ et al. Epigenetic regulation of regulatory $T$ cells in patients with abdominal aortic aneurysm. FEBS Open Bio. 2019;9(6):1137-1143.

131. Toghill BJ, Saratzis A, Harrison SC, Verissimo AR, Mallon EB, Bown MJ. The potential role of DNA methylation in the pathogenesis of abdominal aortic aneurysm. Atherosclerosis. 2015;241(1):121-129.

132. Yin $M$, Zhang J, Wang $Y$ et al. Deficient CD4+CD25+ T regulatory cell function in patients with abdominal aortic aneurysms. Arterioscler Thromb Vasc Biol. 2010;30(9):1825-1831.

133. Halazun KJ, Bofkin KA, Asthana S, Evans C, Henderson M, Spark $\mathrm{Jl}$. Hyperhomocysteinaemia is associated with the rate of abdominal aortic aneurysm expansion. Eur J Vasc Endovasc Surg. 2007;33(4): 391-394. discussion 395-6.

134. Liu Z, Luo H, Zhang L et al. Hyperhomocysteinemia exaggerates adventitial inflammation and angiotensin II-induced abdominal aortic aneurysm in mice. Circ Res. 2012;111(10):1261-1273.

135. Giusti B, Saracini C, Bolli P et al. Genetic analysis of 56 polymorphisms in 17 genes involved in methionine metabolism in patients with abdominal aortic aneurysm. J Med Genet. 2008;45(11): 721-730.

136. Strauss E, Waliszewski K, Gabriel M, Zapalski S, Pawlak AL. Increased risk of the abdominal aortic aneurysm in carriers of the MTHFR 677T allele. J Appl Genet. 2003;44(1):85-93.

137. Krishna SM, Dear A, Craig JM, Norman PE, Golledge J. The potential role of homocysteine mediated DNA methylation and associated epigenetic changes in abdominal aortic aneurysm formation. Atherosclerosis. 2013;228(2):295-305.

How to cite this article: Mangum KD, Farber MA. Genetic and epigenetic regulation of abdominal aortic aneurysms. Clinical Genetics. 2020;97:815-826. https://doi.org/10.1111/cge. 13705 